\title{
$\nsim$ CORRESPONDENCE
}

Carbon monoxide yield of cigarettes

K P Ball, FRCP.............. 731

Self-titration by cigarette smokers

R G Rawbone, MB.............. 731

Alcohol-dependent doctors

M M Glatt, FRCP............ 732

Tetraplegia caused by gymnastics

R F Evans, FrCs............... 732

Nutritional standards and saving money on school meals

A E Bender, PHD ............. 732

Care of children in general practice

G H Curtis Jenkins, MB........... 733

Referral of mothers and infants for

intensive care

M L Chiswick, MD............ 733

Breast or bottle

D W Hide, MRCPED; Helen J Graham, MB;

Carolyn Jones, PHD............ 733

Fetal malnutrition - the price of

upright posture?

A Briend, $M D \ldots \ldots \ldots \ldots \ldots . \ldots . \ldots 74$
Hats for the newborn infant

E C Coles, MB, and H B Valman, FRCP... 734

Kidney transplants and long-term

immunosuppression

B Jones, mB................ 735

Reactions to whooping cough vaccine

J S Robertson, FFCM . . . . . . . . . . . . . 735

Rubella vaccination

N A Black, MB; T S Wilson, FFCM . . . . . . 735

Effects of manufacturing oral

contraceptives on blood clotting

L Poller, FRCPATH, and others. . . . . . . . 735

Serum bilirubin and hepatic enzyme induction

B F Allam, MB . . . . . . . . . . . 736

Volunteer and professional treatments

of dysphasia after stroke

B O Williams, MRCP, and Sandra A Walker,

LCST; Margaret S Meikle, LCST, and Enid

Wechsler, LCST............... 736

Cubital tunnel syndrome

T G Wadsworth, FRCs........... 736
Dangerous antihypertensive treatment Priscilla S Kincaid-Smith, FRCP; J A E Primrose, FRCSED.............. 737

Medicine and the media

W J Elwood, MFCM............... 737

General practice in hospital accident and

emergency departments

Major P J Gravett, MRCPATH......... 737

Fenclofenac-induced nephrotic

syndrome?

J S H Gaston, BM, and P A Dieppe, MRCP. . 738

Psychosocial stress in pregnancy

M O Roland, MRCP............. 738

Spread of steroid-containing foam after

intrarectal administration

M H Irving, FRCs; V T Kelly . . . . . . . . . 738

Design of forms for clinical trials

E A Benson, Frcs. . . . . . . . . . . . . 738

General anaesthesia in sickle-cell disease

J Homi, FFARCS................ 739

Who wants to sit on the GM̈

Sir Graham M Bull, FRCP........... 739

Pre-employment medicals

W Norman-Taylor, mD ........... 739 \section{7} 37 38 738 8 39

We may return unduly long letters to the author for shortening so that we can offer readers as wide a selection as possible. We receive so many letters each week that we have to omit some of them. Letters must be signed personally by all their authors. We cannot acknowledge their receipt unless a stamped addressed envelope or an international reply coupon is enclosed.

\section{Carbon monoxide yield of cigarettes}

SIR,-For the past 10 years evidence has been growing that carbon monoxide $(\mathrm{CO})$ is an important health hazard for smokers. Mainstream cigarette smoke contains from $2^{\circ}$ to $6 \%$ of carbon monoxide and when inhaled and diluted with air it may contain about 400 parts per million of $\mathrm{CO}$, which is eight times greater than the maximum level permitted in industry. Although filter cigarettes tend to have lower tar levels than plain brands, their $\mathrm{CO}$ levels may be higher (if the filters are not ventilated).$^{1-3}$

The reduction of mean tar levels associated with the increase of filter cigarettes in recent years may well have contributed to a fall in lung cancer rates in men under the age of 60 . But the higher CO levels may have led to more deaths from coronary heart disease. Knowledge of carbon monoxide yields is therefore very important. It could also be of value for a patient with coronary heart disease who is unable to stop smoking to smoke a cigarette with a lower $\mathrm{CO}$ rather than a lower tar yield. However, the doctor wishing to advise him is at present unable to do so.

Until now the Government has been unwilling to publish the $\mathrm{CO}$ yields of individual brands of cigarettes, although it is known that they are measured by the Government Chemist. Is the DHSS concerned that the tar and nicotine tables would be too complicated with the addition of $\mathrm{CO}$ levels ? Or is it unwilling to embarrass the industry with the approaching negotiations on "the voluntary agreement" which the industry had with the last Government?

There seem to be no good reasons for withholding information from the profession and anyone else who wishes to know. Publication would have the added advantage of stimulating the industry to lower $\mathrm{CO}$ yields of cigarettes in the same way that tar levels were reduced after the first publication of tar tables. It would also follow the recommendations of the recent WHO report. ${ }^{4}$

\section{Department of Community Medicine,
Middlesex Hospital Medical School,}

Central Middlesex Hospital,

${ }_{1}^{1}$ Russell, M A H, British Medical fournal, 1975, 3, 71. 2 Wald, N J, Lancet, 1976, 1, 136.

Copeland, G K E, paper presented at Fourth World

- Conference on Smoking and Health, June 1979.

Controlling the Smoking Epidemic. Geneva, World Controlling the Smoking E
Health Organisation, 1979 .

\section{Self-titration by cigarette smokers}

SIR,-Dr Heather Ashton and others (11 August, p 357) present results to show selftitration by smokers when they switch from smoking a middle-tar cigarette to either a hightar cigarette or a low-tar cigarette. In that they have employed a wide variety of measurement techniques in a well-balanced study and have shown titration downwards when switching to a higher-tar product (was this passed by an ethical committee ?) their study is interesting. However, the evidence that smokers attempt to compensate for reduced smoke components when switched to a lower-tar product, although admittedly to varying degrees, is consistent throughout all published studies-including our own, ${ }^{1-3}$ in which we demonstrated puff volume, and probably inhalation, to be the important variables. Furthermore, the study by Freedman and Fletcher, ${ }^{2}$ which is quoted as suggesting that smokers "can adapt without compensation to a moderate reduction in nicotine yield" in fact did, on reanalysis of their data, ${ }^{3}$ show that compensation was taking place.

Like other studies in the literature this is another short-term switching study, the measurements reported all being made during the first two weeks following the switch; and the results may be confounded by the fact that the authors have combined results from their two groups-thus mixing, for each analysis, subjects switching from middle-tar control to test product and subjects switching between the two test products.

It seems clear that when subjects switch to a lower-tar product they attempt compensation, but whether this is for the pharmacological effect of nicotine (or any other smoke constituent) or simply because of the reduced impact and flavour of the lower-tar product is an unanswered (and possibly unanswerable) question. What is important is that despite the attempted compensation the intake of nicotine, carbon monoxide, and, by inference, tar is still less than when they were smoking the higher tar product.

What is required is a long-term study of several years' duration to show whether the attempted compensation after switching to lower-tar products persists and, if so, to what extent. Our own published observations, ${ }^{1}$ made on subjects who had smoked either middle-tar or low-tar products for at least two years, would suggest that the compensation does not persist in that the intake of smoke 